University of Nebraska - Lincoln

DigitalCommons@University of Nebraska - Lincoln

Marjorie A. Langell Publications

Published Research - Department of Chemistry

2010

Ni doping of semiconducting boron carbide

\author{
Nina Hong \\ University of Nebraska - Lincoln \\ Marjorie Langell \\ University of Nebraska - Lincoln, mlangell1@unl.edu \\ Jing Liu \\ University of Nebraska - Lincoln \\ Orhan Kizilkaya \\ Louisiana State University at Baton Rouge, orhan@lsu.edu \\ Shireen Adenwalla \\ University of Nebraska - Lincoln, sadenwalla1@unl.edu
}

Follow this and additional works at: https://digitalcommons.unl.edu/chemistrylangell

Part of the Chemistry Commons

Hong, Nina; Langell, Marjorie; Liu, Jing; Kizilkaya, Orhan; and Adenwalla, Shireen, "Ni doping of semiconducting boron carbide" (2010). Marjorie A. Langell Publications. 23.

https://digitalcommons.unl.edu/chemistrylangell/23

This Article is brought to you for free and open access by the Published Research - Department of Chemistry at DigitalCommons@University of Nebraska - Lincoln. It has been accepted for inclusion in Marjorie A. Langell Publications by an authorized administrator of DigitalCommons@University of Nebraska - Lincoln. 


\title{
Ni doping of semiconducting boron carbide
}

\author{
Nina Hong (이니나), ${ }^{1}$ M. A. Langell, ${ }^{2}$ Jing Liu, ${ }^{1}$ Orhan Kizilkaya ${ }^{3}$ and S. Adenwalla, ${ }^{1, a)}$ \\ ${ }^{1}$ Department of Physics and Astronomy, University of Nebraska-Lincoln, Lincoln, Nebraska \\ 68588-0511, USA \\ ${ }^{2}$ Department of Chemistry, University of Nebraska-Lincoln, Lincoln, Nebraska 68588-0304, USA \\ ${ }^{3}$ Center for Advanced Microstructures and Devices, Louisiana State University, 6980 Jefferson Highway, \\ Baton Rouge, Louisiana 70806, USA
}

(Received 21 August 2009; accepted 7 December 2009; published online 27 January 2010)

\begin{abstract}
The wide band gap, temperature stability, high resistivity, and robustness of semiconducting boron carbide make it an attractive material for device applications. Undoped boron carbide is $\mathrm{p}$ type; $\mathrm{Ni}$ acts as a n-type dopant. Here we present the results of controlled doping of boron carbide with $\mathrm{Ni}$ on thin film samples grown using plasma enhanced chemical vapor deposition. The change in the dopant concentration within the thin film as a function of the dopant flow rate in the precursor gas mixture was confirmed by x-ray photoelectron spectroscopy measurements; with increasing dopant concentration, current-voltage (I-V) curves clearly establish the trend from p-type to n-type boron carbide. (C) 2010 American Institute of Physics. [doi:10.1063/1.3284205]
\end{abstract}

\section{INTRODUCTION}

In the development of a semiconductor, the ability to control both $\mathrm{n}$ - and p-type doping is of paramount importance for device applications. ${ }^{1}$ The development of a semiconducting form of boron carbide has resulted in heterojunction diodes, a junction gate field-effect-transistor (JFET), ${ }^{2}$ Esaki-type tunnel diodes, ${ }^{3}$ homojunction diodes, heterojunction neutron detectors, ${ }^{4,5}$ and a high temperature heterojunction diode with $\mathrm{SiC}^{6}$ Semiconducting boron carbide devices have been found to be valuable in a variety of unique device applications. Chief among them are solid state neutron detectors due to the high cross section of ${ }^{10} \mathrm{~B}$ for thermal neutrons ${ }^{7}$ and the ability to both capture neutrons and sweep out charge in the same material. In addition, the high resistivity and dielectric constant of boron carbide $(\sim 8)$ make it eminently suitable as a tunneling barrier for magnetic tunnel junctions. Photoemission studies of boron carbide/Co interfaces show no quenching of the Co magnetic moment at the interface, an important consideration for spintronic applications. ${ }^{8}$ Controlled doping of the boron carbide barrier layer will allow for precise positioning of the Fermi level, hence changing the tunneling characteristics.

In the absence of intentional doping, boron carbide is a p-type semiconductor with a resistivity of $\sim 10^{10} \Omega \mathrm{cm}$ at room temperature. $\mathrm{Ni}$ has been found to be an excellent n-type dopant, ${ }^{9,3}$ and boron carbide homojunction diodes have been made using Ni doped n-type and undoped p-type boron carbide. In this letter, we report on the controlled doping of semiconducting boron carbide. The correlation between increasing $\mathrm{Ni}$ concentration and n-type semiconducting characteristics is confirmed by $\mathrm{x}$-ray photoelectron spectroscopy (XPS) and I-V measurement. Ni doping results in a significant upward shift of the Fermi level and does not

\footnotetext{
a) Author to whom correspondence should be addressed. Electronic mail: sadenwalla1@unl.edu.
}

lead to significant changes in the surface quality; however, $\mathrm{x}$-ray diffraction (XRD) results indicate a change in the crystallinity.

\section{EXPERIMENTAL DETAILS}

The plasma enhanced chemical vapor deposition (PECVD) growth of semiconducting boron carbide films has been well documented. ${ }^{6}$ PECVD lends itself quite easily to good control of the dopant density if a suitable precursor molecule can be found. $\mathrm{C}_{2} \mathrm{~B}_{10} \mathrm{H}_{12}$ (orthocarborane) is used as the precursor molecule for boron carbide deposition, and $\mathrm{Ni}\left(\mathrm{C}_{5} \mathrm{H}_{5}\right)_{2}$ (nickelocene) ${ }^{10}$ as the source molecule for introduction of the Ni dopant. A vial of nickelocene in parallel with the orthocarborane vial (at a temperature of $90^{\circ} \mathrm{C}$ ) is inserted into the gas handling system and maintained at a temperature of $27^{\circ} \mathrm{C}$. The argon gas flow through the two vials is varied, as shown in Table I. The ratio of the two precursors in the mix will depend on the respective vapor pressures and inlet and outlet tube geometries and must be a monotonic function of the relative gas flows since all other variables remain unchanged. The vapor pressures of nickelocene and orthocarborane as a function of temperature are well known, ${ }^{11,12}$ giving a ratio of 0.001135 atoms of Ni per molecule of orthocarborane $(\sim 0.11 \%)$ for a dilution ratio of 1. For all other dilution ratios, the proportion of $\mathrm{Ni}$ in the gas mix will rise in proportion to the argon gas flow. Hence for the 9:1 dilution ratio, the incoming gas will contain $1 \%$ of Ni. Two series of samples were made, one on n-type Si with a measured resistivity of $100 \Omega \mathrm{cm}$ corresponding to a dopant density of $4.5 \times 10^{13} \mathrm{~cm}^{-3}$ and one on p-type $\mathrm{Si}$ with a resistivity of $16 \Omega \mathrm{cm}$ corresponding to a dopant density of $1 \times 10^{15} \mathrm{~cm}^{-3}$. At each dilution ratio, the samples on the n-type and p-type Si were grown simultaneously in the same chamber; hence we expect the film compositions on the two different substrates to be identical. X-ray reflectivity data, which are not shown, indicated the same growth rate $(\sim 10 \mathrm{~nm} / \mathrm{min})$ for each sample when the Ar flow rate through the orthocarborane vial is fixed. Substrates were 
TABLE I. Ar gas flow through the orthocarborane and nickelocene vials for all samples. The dilution ratio is defined as the ratio of Ar gas flow through the nickelocene vial to Ar gas flow through the orthocarborane vial. The Ni concentration in the gas phase increases with increasing dilution ratio.

\begin{tabular}{lcccccc}
\hline \hline Sample name & BC & Ni(1)-BC & Ni(3)-BC & Ni(5)-BC & Ni(7)-BC & Ni(9)-BC \\
\hline Orthocarborane & $1 \mathrm{SCCM}$ & $1 \mathrm{SCCM}$ & $1 \mathrm{SCCM}$ & $1 \mathrm{SCCM}$ & 1 SCCM & 1 SCCM \\
Nickelocene & $0 \mathrm{SCCM}$ & $1 \mathrm{SCCM}$ & $3 \mathrm{SCCM}$ & $5 \mathrm{SCCM}$ & $7 \mathrm{SCCM}$ & 9 SCCM \\
Dilution ratio & 0 & 1 & 3 & 5 & 7 & 9 \\
\hline \hline
\end{tabular}

cleaned using acetone, methanol, de-ionized water, and 5\% $\mathrm{HF}$ before insertion into the PECVD reactor. Inside the reactor, a $30 \mathrm{~min} \mathrm{Ar}$ ion etch was performed prior to deposition. All samples were deposited at a substrate temperature of $330{ }^{\circ} \mathrm{C}$ for $1 \mathrm{~h}$, leading to films that are $600 \mathrm{~nm}$ thick.

The structural properties of undoped and doped boron carbide were compared by atomic force microscope (AFM) and $\theta-2 \theta$ XRD scans using $\mathrm{Cu} \mathrm{K} \alpha$ radiation $(\lambda=1.54 \AA)$ at room temperature. The relative Ni concentrations as a function of the Ni source molecule's flow rate were investigated by XPS measurements using a Physical Electronics 04-548 dual $\mathrm{x}$-ray anode with unmonochromatized $\mathrm{Mg} \mathrm{K} \alpha$ radiation. The photoemission was energy analyzed with an Omnicron EA 125 concentric hemispherical analyzer operating at a constant pass energy of $15 \mathrm{eV}$ for carbon, boron, and oxygen, and $50 \mathrm{eV}$ for nickel. The spectra were taken in $0.1 \mathrm{eV}$ increments and were averaged for 25-50 scans. Binding energies were calibrated to adventitious carbon, with $\mathrm{C} 1 \mathrm{~s}$ taken to be $284.6 \mathrm{eV}$. In situ surface treatment could be performed with inert ion bombardment with a Physical Electronics 04303 differentially pumped ion source. Ion sputtered substrates were treated using $3 \mathrm{kV} \mathrm{Ar}{ }^{+}$in normal incidence mode for $40 \mathrm{~min}$, leading to the removal of $\sim 20 \mathrm{~nm}$ of surface material. The $\mathrm{x}$-ray absorption near edge structure (XANES) spectra were undertaken at the double crystal monochromator (DCM) beamline at the Center for Microstructures and Devices (CAMD). Monochromatic light was obtained by using a DCM of Lemonnier type, ${ }^{13}$ equipped with $\mathrm{Ge}(220)$ crystal pair with an overall resolution of $\sim 2 \mathrm{eV}$. The fluorescence yield mode utilizing a Canberra 13-element high purity germanium diode array detector was used to collect the XANES data. The monochromator was calibrated at the Ni K edge at $8333 \mathrm{eV}$ using a Ni foil.

The variations in semiconducting properties were established from the I-V curves of each heterojunction diode. Circular $\mathrm{Ohmic} \mathrm{Cr} / \mathrm{Au}$ contacts with diameters ranging from 1 to $5 \mathrm{~mm}$ were sputter deposited on both sides of the boron carbide/Si heterojunction.

\section{RESULTS AND DISCUSSION}

The structure of the interface is an important parameter in the development of tunnel junctions and homojunction diodes. The AFM images of undoped (left) and highly doped (right) boron carbide films on Si substrates in Fig. 1 indicate rms roughnesses of 2.1 and $2.5 \mathrm{~nm}$, respectively. High dopant concentrations have no discernible effect on the surface roughness, leading us to conclude that PECVD is a viable method for the growth of homojunction diodes and highly doped tunnel junctions.

XRD scans are shown in Fig. 2 for a subset of the samples. The undoped and lightly doped films show X-ray peaks at $2 \vartheta \sim 23.5^{\circ}$ and $43^{\circ}$ and typical crystallite sizes of $\sim 10 \mathrm{~nm}$, substantially less than the film thickness of 600 nm. ${ }^{6}$ Two key differences between these two films are observed: in the undoped film, the peak at $43^{\circ}$ consists of two
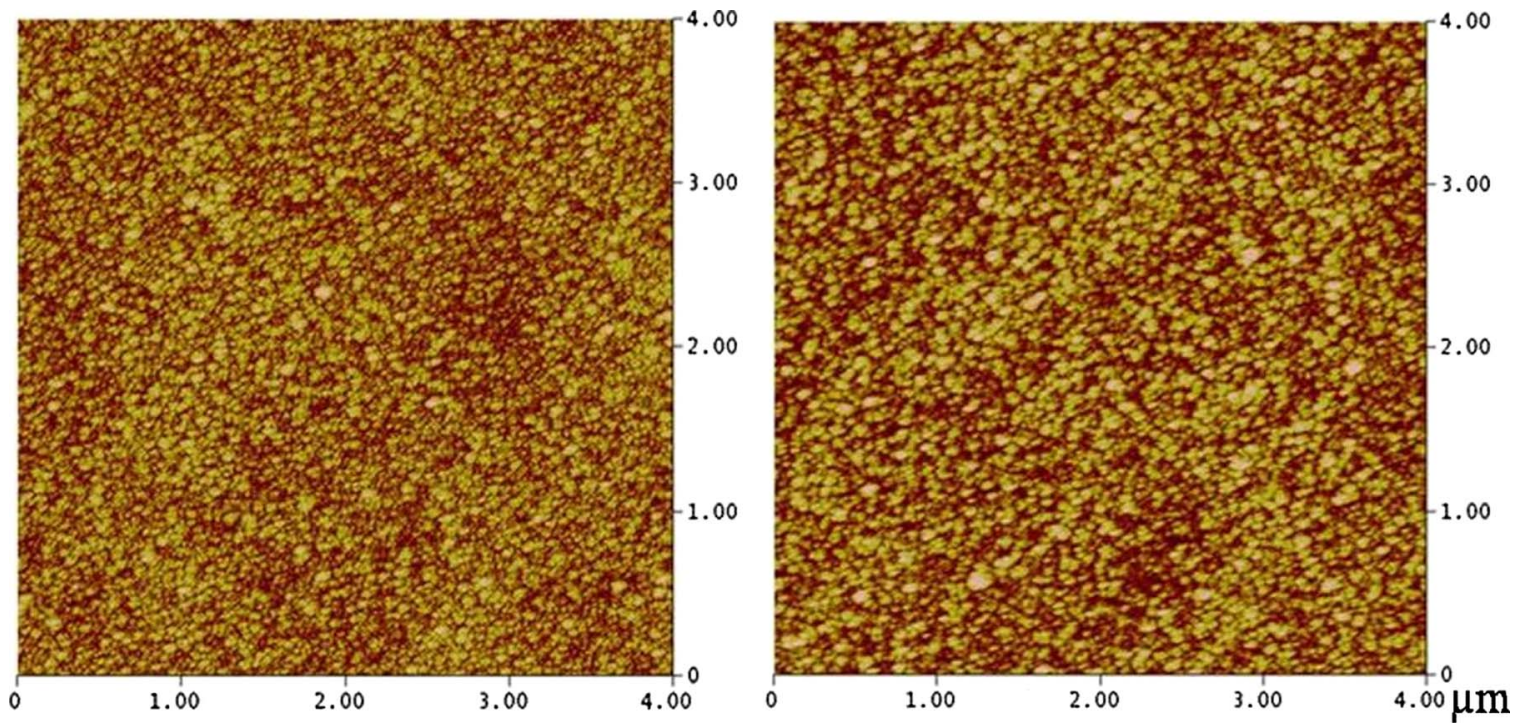

FIG. 1. (Color online) AFM images for BC (left) and Ni(9)-BC (right) on Si substrates, showing no significant change in the surface quality. rms roughness values are $2.1 \mathrm{~nm}$ for $\mathrm{BC}$ and $2.5 \mathrm{~nm}$ for $\mathrm{Ni}(9)-\mathrm{BC}$. The $\mathrm{z}$ range is $15 \mathrm{~nm}$. 


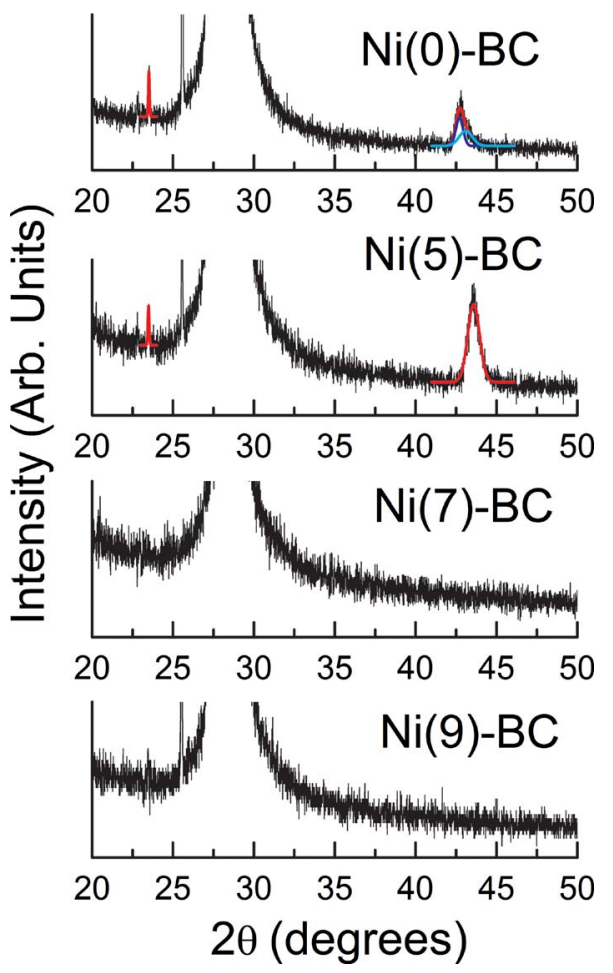

FIG. 2. (Color online) XRD data for $\mathrm{Ni}(0,5,7$, and 9)-BC films on $\mathrm{Si}$ substrates over a selected region $\left(20^{\circ}-50^{\circ}\right)$ chosen to optimally display the BC peaks. The $\mathrm{Si}(111)$ and $\mathrm{SiO}_{2}$ peaks are at $28.5^{\circ}$ and $25.5^{\circ}$, respectively. Undoped $\mathrm{BC}$ and $\mathrm{Ni}(5)-\mathrm{BC}$ show diffraction peaks at $23.5^{\circ}$ and $43^{\circ}$. The peak at $43^{\circ}$ in the undoped sample consists of two peaks at $42.7^{\circ}$ and $43.0^{\circ}$ with almost equal intensities. In the $\mathrm{Ni}(5)-\mathrm{BC}$ sample, a single peak at $43.59^{\circ}$ is seen. The relative intensities of the $\mathrm{x}$-ray peaks are obtained from Gaussian fits shown. No peaks are seen for $\mathrm{Ni}(7)-\mathrm{BC}$ and $\mathrm{Ni}(9)-\mathrm{BC}$.

barely resolved peaks at $42.7^{\circ}$ and $43^{\circ}$, whereas in the lightly doped sample, only a single peak at $43.59^{\circ}$ is seen. The ratio of the intensities of the two peaks (at $43^{\circ}$ and $23^{\circ}$ ) changes from $\sim 7.5$ for the undoped sample to 17 for the lightly doped sample. The more highly doped BC films show no XRD peaks, implying that the addition of Ni leads to yet further disruption of the crystalline structure. Similar effects have been seen in sputtered semiconducting thin films and have been attributed to decreasing crystallite size with increasing dopant concentration. ${ }^{14}$ Identification of the crystal structures of boron carbide based on x-ray data is fraught with difficulty, owing to the plethora of similar crystal structures that may differ only in the placement of $\mathrm{C}$ atoms and/or small differences in the size of the unit cell (and hence the position of the diffraction peak). All are based on the structure of icosahedral B, with the icosahedra at the corners and/or faces of rhombohedral and tetrahedral unit cells. Restricting ourselves to a single polytype, the positions of the split peak at $43^{\circ}$ for the undoped sample and the peak at $23^{\circ}$ indicate a structure similar to the crystal structure for orthorhombic $\mathrm{B}_{8} \mathrm{C} .{ }^{15}$ Differences in the relative intensities as compared to the powder pattern may be attributed either to a preferential growth direction or to the presence of two C atoms in the icosahedra from the precursor molecule. At low levels of Ni doping, the crystallite sizes are not reduced, but the change in the relative intensities may imply a change in the preferred orientation. n-type doping of rhombohedral bo-
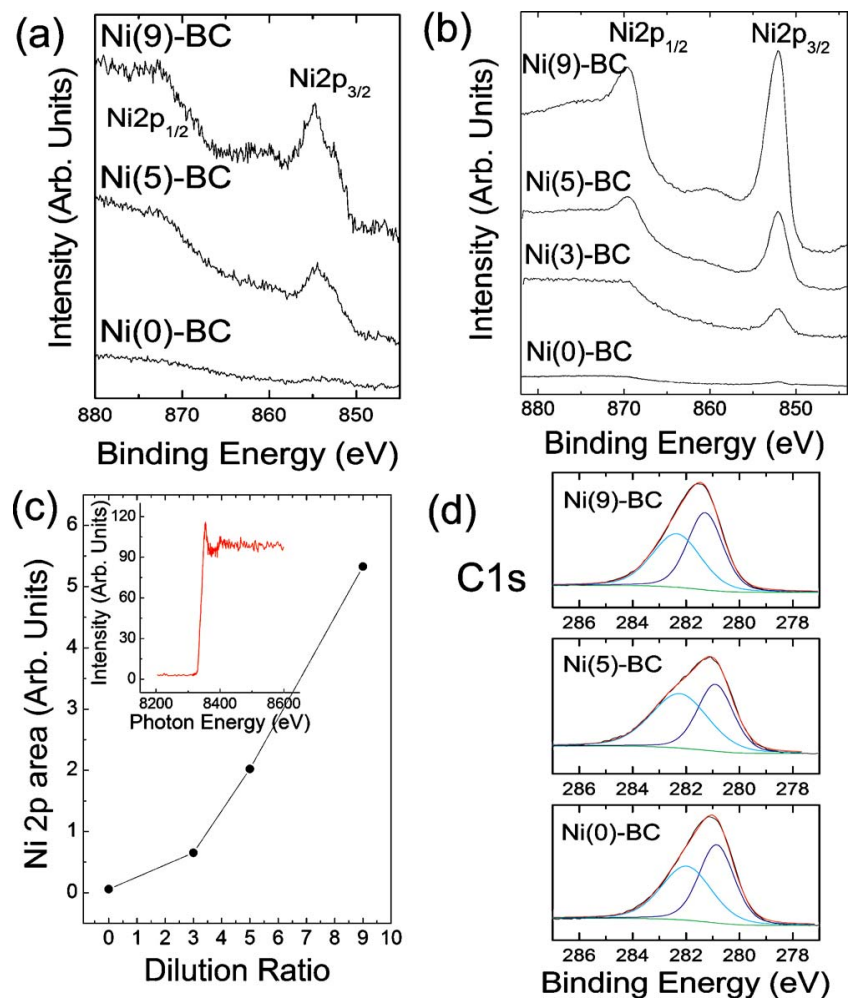

FIG. 3. (Color online) Ni2p XPS spectrum (a) before and (b) after sputtering to remove surface contaminants. Measurements of the surface before sputtering indicate the presence of $\mathrm{NiO}$. After sputtering, the peak shape is similar to that of metallic Ni. (c) Plot of the Ni2p peak area as a function of dilution ratio. The Ni peak intensity is normalized to the area under the corresponding $\mathrm{B} 1 \mathrm{~s}$ peak. Increasing the ratio of $\mathrm{Ni}$ in the gas phase leads to a corresponding increase in $\mathrm{Ni}$ concentration in the thin films. The inset shows the XANES data of a Ni(7)-BC thin film, showing the Ni edge close to the expected energy of $8333 \mathrm{eV}$. (d) C1s XPS spectrum after sputtering, showing the absence of graphitic carbon in both undoped and $\mathrm{Ni}$ doped boron carbide.

ron with transition metal elements ${ }^{16}$ in powder samples indicates that the transition metal elements enter interstitial sites, while maintaining the overall crystal structure, at concentrations far higher than in the present samples. Extended x-rayabsorption fine structure and XANES measurements of Co doped boron carbide at concentrations of $\sim 1 \%$ (Ref. 17) are consistent with Co atoms replacing one of the icosahedral atoms. As we shall show below, the $\mathrm{Ni}$ atom concentrations in the present samples are well below this range, and hence structural information on the position of the $\mathrm{Ni}$ atoms is hard to obtain.

To investigate the presence of $\mathrm{Ni}$ atoms in the semiconducting thin film, both XPS and XANES measurements are shown in Fig. 3. The Ni2p region shown in Fig. 3(b) was obtained after Ar ion sputtering, showing peaks that are characteristic of metallic Ni with low satellite structure and binding energies of $2 \mathrm{p}_{3 / 2}=852.1 \mathrm{eV}$ and $2 \mathrm{p}_{1 / 2}=869.5 \mathrm{eV}$ comparable to literature spectra for the metal, ${ }^{18}$ consistent with the interstitial sites shown previously for transition metal dopants. ${ }^{16,19}$ Similar measurements taken before surface sputtering [Fig. 3(a)] showed the existence of $\mathrm{NiO}$ with $2 \mathrm{p}_{3 / 2}=854.5 \mathrm{eV}$ and $2 \mathrm{p}_{1 / 2}=872.2 \mathrm{eV}$ and strong, characteristic satellite structure, indicating the presence of surface oxides. To calculate relative surface concentrations, the Ni2 $\mathrm{p}_{3 / 2}$ 
peak in the sputtered samples is normalized by the total area of the B1s peak intensity obtained on the same sample and this normalized peak intensity is shown in Fig. 3(c) as a function of the nickelocene flow rate. Since a fixed Ar flow rate through the orthocarborane vial was used (resulting in the same growth rate for each sample), we assume a constant quantity of boron within the film. The undoped sample shows $\mathrm{Ni}$ peak intensities barely above the noise level. As the nicklocene ratio increases, so too does the relative $\mathrm{Ni}$ concentration, leading us to conclude that the atomic ratios in the thin film are essentially proportional to the gas phase ratios. XANES measurements of the characteristic absorption edge of nickel at a value close to the expected $8333 \mathrm{eV}$ of the Ni K edge are shown in the inset of Fig. 3(c) on the $7: 1$ sample, providing additional confirmation of the presence of $\mathrm{Ni}$ within the film. The shape of the signal is distinct from that of pure $\mathrm{Ni}$, indicating hybridization of the $\mathrm{Ni}$ atoms. Exact details of the hybridization will require samples with much higher doping levels. The detection limit for this XANES setup is $10 \mathrm{ppm}$, and an order of magnitude estimate of the amount of $\mathrm{Ni}$ in the sample indicates a level of $\sim 0.1 \%$, significantly reduced from the proportion of $\mathrm{Ni}$ atoms in the precursor gas mix, which is calculated at close to $0.8 \%$. These minute quantities of dopant atoms have a significant effect on the electronic properties, a characteristic of doping, quite distinct from the Co and Fe doped BC films, ${ }^{19}$ with far higher impurity concentrations of $\sim 1 \%$ within the film.

Concerns regarding the $\mathrm{C}$ content of the nickelocene precursor molecule and its effects on the BC structure were probed by XPS measurements of the $\mathrm{C} 1 \mathrm{~s}$ peak as a function of Ni doping. We looked for both an increase in graphitic carbon and changes in the icosahedral cage. Figure 3(d) shows $\mathrm{C} 1$ s peaks for the $\mathrm{Ni}(0,5,9)$-BC samples after $\mathrm{Ar}^{+}$ion sputtering. Each peak was fitted (using a 25\% LorentzianGaussian function) to two separate peaks. The first peak at $281.0 \mathrm{eV}$ corresponds to the $\mathrm{C}-\mathrm{B}-\mathrm{C}$ chain and the second peak at $282.2 \mathrm{eV}$ corresponds to the $\mathrm{B}_{11} \mathrm{C}$ icosahedral cage. $^{20,21}$ There is no substantial change in the ratio or position of the two peaks on increasing the $\mathrm{Ni}$ concentration from 0 to the highest doped 9:1 sample. Moreover, unlike sputter deposited BC films, ${ }^{20,21}$ these PECVD grown boron carbide films do not show the presence of the characteristic graphite peak at $\sim 284.4 \pm 0.2 \mathrm{eV}$, either with or without the addition of $\mathrm{Ni}$. This is consistent with the much higher resistivity of the PECVD (Ref. 22) grown samples as compared to hot-pressed ${ }^{23}$ and sputter deposited ${ }^{20,21}$ BC samples.

With increased concentrations of dopant atoms, distinct changes in the electronic properties are apparent in the room temperature I-V curves of the complete series of heterojunction diodes, as shown in Fig. 4. Positive voltage is applied to the p-type layer, i.e., boron carbide layer (p-type Si layer) in the left (right) panel. The figure dramatically illustrates the effect of increased doping. Undoped boron carbide on n-type $\mathrm{Si}$ forms excellent diodes. Looking from top to bottom in the left panel for n-type Si substrates, the diode quality worsens with increased $\mathrm{Ni}$ doping, until at a dilution ratio of $1: 9$, the $\mathrm{I}-\mathrm{V}$ curve reverses. In contrast, in the right panel for p-type $\mathrm{Si}$ substrates, the diode properties improve with increased $\mathrm{Ni}$
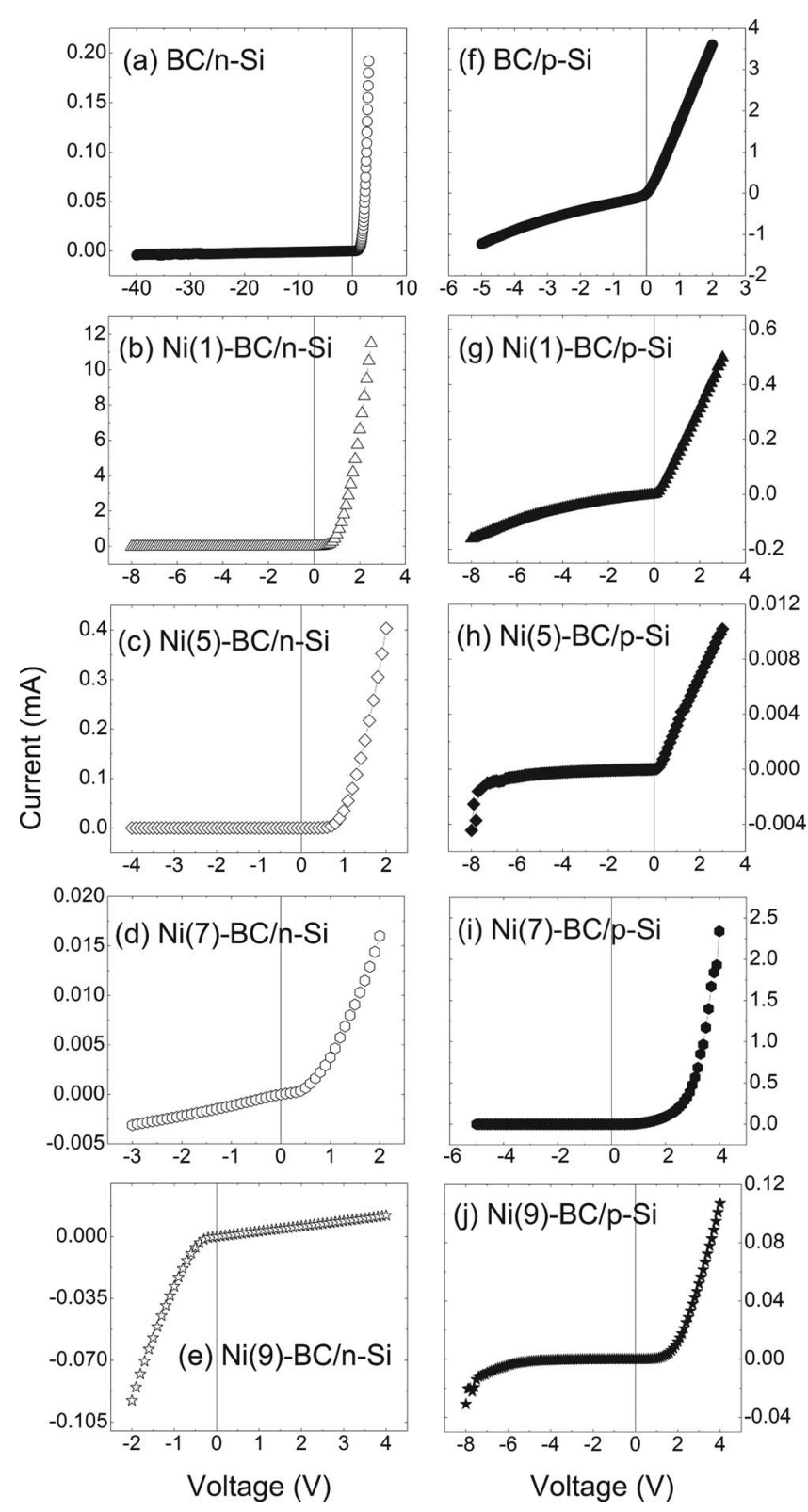

FIG. 4. Current-voltage (I-V) curves of $\mathrm{Ni}(\mathrm{X})-\mathrm{BC}(\mathrm{X}=0,5,7$, and 9) on n-type Si [(a)-(e) left hand column] and on p-type Si [(f)-(j) right hand column] at room temperature, showing clear evidence for the trend toward n-type behavior at higher doping concentrations.

doping. Clearly, increasing the concentration of Ni results in a substantial increase in n-type character.

The forward biased turn on voltage $\mathrm{V}_{\mathrm{bi}}$ is a measure of the difference in Fermi levels between two isolated semiconductors; in our case, $\mathrm{Si}$ and $\mathrm{BC}$ changes in $\mathrm{V}_{\mathrm{bi}}$ reflect a change in the Fermi level, a signature of doping. The net increase in $\mathrm{V}_{\mathrm{bi}}$ in going from the undoped, p-type $\mathrm{BC}$ to the highest $\mathrm{Ni}$ doping concentration is $0.8 \mathrm{~V}$, raising the Fermi level by $0.8 \mathrm{eV}$, a significant fraction of the optically measured band gap of $2.2 \mathrm{eV}$ in $\mathrm{BC}$. In terms of energies,

$$
\mathrm{qV}_{\mathrm{bi}}=\mathrm{q} \chi^{\mathrm{BC}}+\left(\mathrm{E}_{\mathrm{c}}^{\mathrm{BC}}-\mathrm{E}_{\mathrm{F}}^{\mathrm{BC}}\right)-\left[\mathrm{q} \chi^{\mathrm{Si}}+\left(\mathrm{E}_{\mathrm{c}}^{\mathrm{Si}}-\mathrm{E}_{\mathrm{F}}^{\mathrm{Si}}\right)\right],
$$

where $\chi, \mathrm{E}_{\mathrm{C}}$, and $\mathrm{E}_{\mathrm{F}}$ are the electron affinities, the conduction band energies, and the Fermi levels in each semiconductor. 


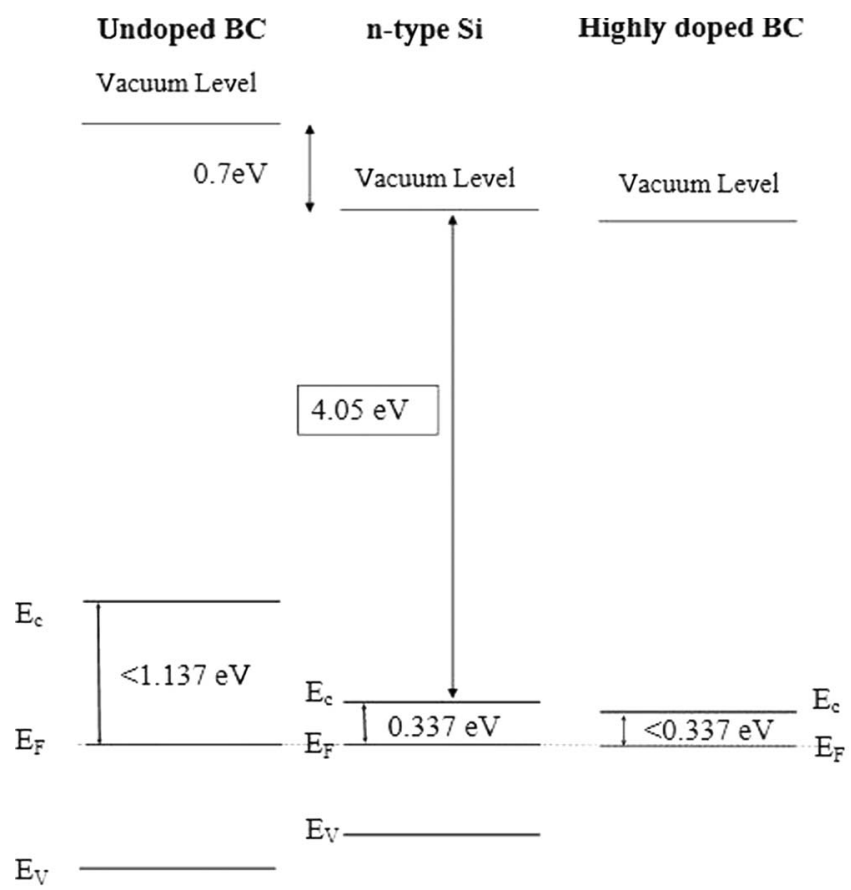

$E_{V}$

FIG. 5. Energy band diagram of undoped $\mathrm{BC}$, n-type $\mathrm{Si}$, and highly $\mathrm{Ni}$ doped BC. The electron affinity for BC is unknown. The constraints on the positions of the Fermi level in the $\mathrm{BC}$ arise from the behavior of the I-V curves with increased doping. All quantities for the Si substrate are well known. For details see text.

Although the electron affinity and the position of the Fermi level are not known for the BC film, we can tentatively draft a possible band structure for the $\mathrm{Si} / \mathrm{BC}$ heterojunction diodes if we assume that the electron affinity and band gap do not change with doping, i.e., that we are in the nondegenerate limit. For the $\mathrm{BC}$ on n-type $\mathrm{Si}$ - the $\mathrm{I}-\mathrm{V}$ curves in the left column-the diode curve reverses at the highest doping concentration studied, providing an important quantifiable piece of evidence for placement of the energy bands. The Fermi level for the n-type Si substrate is 0.337 $\mathrm{eV}$ below the conduction band. The Fermi level for the BC film is below this level until a doping concentration corresponding to a dilution ratio of $>7$ is reached. At a dilution ratio of 9 , the $I-V$ curve reverses, implying that it is now easier for electrons to diffuse from the BC to the $\mathrm{Si}$. Together with the knowledge of the band gap of BC and the shift in the Fermi level upward by $0.8 \mathrm{eV}$, the final Fermi levels are tightly constrained and are shown graphically in Fig. 5 for the $\mathrm{BC} / \mathrm{Si}$ heterojunction. At equilibrium, the Fermi levels are constant across the heterojunction. The I-V curve indicates that $\mathrm{E}_{\mathrm{c}}{ }^{\mathrm{BC}}$ is higher than $\mathrm{E}_{\mathrm{c}} \mathrm{Si}$ until a dilution ratio of 9 is reached, at which point the Fermi level in the $\mathrm{BC}$ has shifted upward toward the conduction band by $0.8 \mathrm{eV}$ and $\mathrm{E}_{\mathrm{C}}{ }^{\mathrm{BC}}$ is lower than $\mathrm{E}_{\mathrm{c}}^{\mathrm{Si}}$. Algebraically, we can express this as

$$
\begin{aligned}
& \left(\mathrm{E}_{\mathrm{c}}-\mathrm{E}_{\mathrm{F}}\right)_{\text {for undoped } \mathrm{BC}}-0.8 \mathrm{eV} \\
& \quad<\left(\mathrm{E}_{\mathrm{c}}-\mathrm{E}_{\mathrm{F}}\right)_{\text {for the given n-type Si }},
\end{aligned}
$$

which implies that for undoped $\mathrm{BC}$ the Fermi level can be at most $0.037 \mathrm{eV}$ below midgap, very close to intrinsic (note

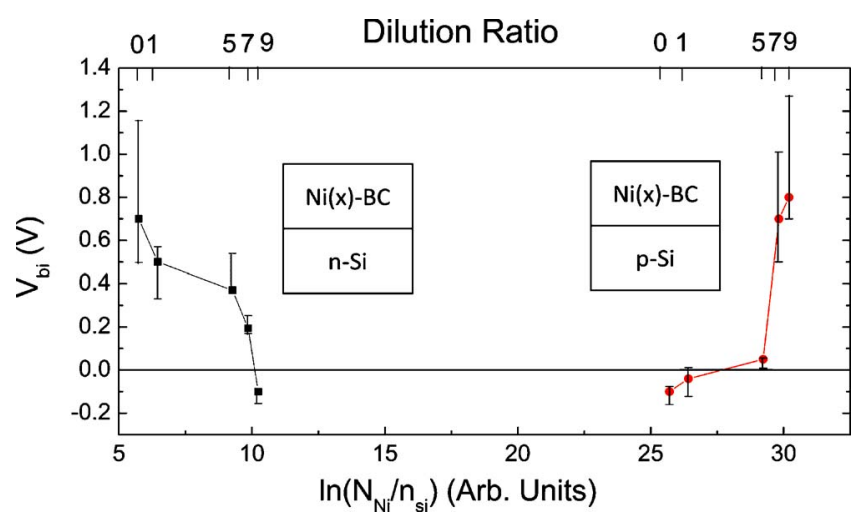

FIG. 6. (Color online) The plots of built-in potential vs natural log of relative Ni concentration normalized by the electron carrier concentration of n(or p)-type Si. The top scale shows the dilution ratio, increasing to the right. Since $\mathrm{n}_{\mathrm{Si}}$ for the $\mathrm{p}$-type $\mathrm{Si}$ substrate is much smaller than that for the $\mathrm{n}$-type substrate, all data on the p-type $\mathrm{Si}$ are shifted to the right. The nonlinearity of these curves indicates that the carrier concentration $\mathrm{n}$ in the $\mathrm{BC}$ layer is not proportional to the dopant concentration $\mathrm{N}_{\mathrm{D}}$.

that we have neglected the effects of the interface dipole potential, a correction which amounts to $\sim 0.1 \mathrm{eV}$ for most heterojunctions ${ }^{24}$ ). A similar structure for the p-type Si substrate, in which the Fermi level is $0.245 \mathrm{eV}$ above the valence band, may also be constructed.

For crystalline heterojunction diodes in the nondegenerate limit, the relationship between the energy levels and doping concentrations is straightforward and $\mathrm{V}_{\mathrm{bi}}$ is given by

$$
\mathrm{V}_{\mathrm{bi}}=\Delta \chi+\frac{\mathrm{kT}}{\mathrm{q}} \ln \left[\frac{\mathrm{n}_{\mathrm{n}} \mathrm{N}_{\mathrm{c}, \mathrm{p}}}{\mathrm{n}_{\mathrm{p}} \mathrm{N}_{\mathrm{c}, \mathrm{n}}}\right],
$$

where $\Delta \chi$ is the difference in electron affinity values, $\mathrm{n}_{\mathrm{n}}\left(\mathrm{n}_{\mathrm{p}}\right)$ are the electron carrier concentrations, and $\mathrm{N}_{\mathrm{c}, \mathrm{n}}\left(\mathrm{N}_{\mathrm{c}, \mathrm{p}}\right)$ are the effective density of states at the conduction band edge on the $\mathrm{n}(\mathrm{p})$ sides of the junction. A similar expression exists for the hole concentration and the density of states at the valence band. The relative increase in carrier concentration is apparent in Fig. 6, a plot of $\mathrm{V}_{\mathrm{bi}}$ versus the $\log$ of the relative $\mathrm{Ni}$ concentration (as obtained from XPS) normalized to the $\mathrm{Si}$ carrier density.

For the junctions on n-type $\mathrm{Si}$, we can rewrite Eq. (3) as

$$
\mathrm{V}_{\mathrm{bi}}=-\Delta \chi-\frac{\mathrm{kT}}{\mathrm{q}} \ln \left[\frac{\mathrm{N}_{\mathrm{c}, \mathrm{Si}}}{\mathrm{N}_{\mathrm{c}, \mathrm{BC}}}\right]-\frac{\mathrm{kT}}{\mathrm{q}} \ln \left[\frac{\mathrm{n}_{\mathrm{BC}}}{\mathrm{n}_{\mathrm{Si}}}\right],
$$

and for those on p-type $\mathrm{Si}$

$$
\mathrm{V}_{\mathrm{bi}}=\Delta \chi+\frac{\mathrm{kT}}{\mathrm{q}} \ln \left[\frac{\mathrm{N}_{\mathrm{c}, \mathrm{Si}}}{\mathrm{N}_{\mathrm{c}, \mathrm{BC}}}\right]+\frac{\mathrm{kT}}{\mathrm{q}} \ln \left[\frac{\mathrm{n}_{\mathrm{BC}}}{\mathrm{n}_{\mathrm{Si}}}\right] .
$$

$\mathrm{V}_{\mathrm{bi}}$ is plotted against the natural log of the relative $\mathrm{Ni}$ concentration obtained from XPS, normalized to the electron carrier concentration of $\mathrm{n}$ - or p-type Si. Assuming that $\mathrm{Ni}$ doping leaves both the electron affinity and the density of states unchanged and that the n-type carrier concentration in $\mathrm{BC}$ is a linear function of the Ni concentration, both sets of data should lie on straight lines with a negative slope for the diodes on n-type $\mathrm{Si}$ and a positive slope for those on p-type Si. Clearly, this is not the case, leading to the conclusion of a more complex relationship between the Fermi level and doping concentration. Even in the case of purely crystalline 
semiconductors, $N_{D}=n$ is only true when $N_{D} \gg N_{A}$. In the case of doped $\mathrm{BC}$, in which the undoped material has p-type characteristics, there must be doping concentrations at which $\mathrm{N}_{\mathrm{D}} \approx \mathrm{N}_{\mathrm{A}}$, in which case the entire expression for

$$
\mathrm{n}=\frac{\mathrm{N}_{\mathrm{D}}^{+}-\mathrm{N}_{\mathrm{A}}^{-}}{2}+\sqrt{\left(\frac{\mathrm{N}_{\mathrm{D}}^{+}-\mathrm{N}_{\mathrm{A}}^{-}}{2}\right)^{2}+\mathrm{n}_{\mathrm{i}}{ }^{2}}
$$

is necessary. In the case of amorphous and microcrystalline semiconductors in which there exists a small albeit finite density of states in the gap, the shift in the Fermi level due to doping is dominated by the expression

$$
\mathrm{N}_{\mathrm{D}}^{+}=\int \frac{\mathrm{g}(\varepsilon)}{1+\mathrm{e}^{\left(\varepsilon-\varepsilon_{\mathrm{F}}\right)}} \mathrm{d} \varepsilon
$$

where $\mathrm{N}_{\mathrm{D}}{ }^{+}$is the density of fully ionized dopants in the semiconductor ${ }^{25}$ and the limits of integration extend from the Fermi level of the undoped semiconductor to the conduction band edge. In these semiconductors, changes in the electronic properties arise from changes in the occupation of states within the gap. Paradoxically, as elucidated by Spear, ${ }^{25}$ in order for small concentrations of dopant atoms to produce visible changes in the electronic properties, it is necessary that the density of states in the gap is low. Preliminary photoemission measurements of this entire series of samples indicate minimal tailing and a well-defined gap with a negligible density of states within the gap.

Complex doping mechanisms have been noted in amorphous, ${ }^{26}$ microcystalline, ${ }^{27}$ and polycrystalline Si (Ref. 28 ) in which the interaction between dopant atoms, local defects, and hydrogen passivation controls the doping efficiency. Hydrogen plays an important role in passivating defects, thus enabling the structural sensitivity necessary for doping in the amorphous material. In polycrystalline $\mathrm{Si}$, at low dopant atom concentrations, there is no change in carrier concentration; the dopant atoms play the role of defect compensation, and changes in carrier concentrations are noted only at higher dopant atom concentrations. As is the case in $\mathrm{Si}: \mathrm{H}$, the CVD growth process for doping boron carbide using hydrogen rich precursor gases (specifically nickelocene) is the potential source for the introduction of hydrogen into the film. We note, however, that in previous experiments using PECVD grown films of $\mathrm{BC}$ doped with nickelocene, IR measurements indicate no significant increase in the intensity of the $\mathrm{BH}$ or $\mathrm{CH}$ bond with doping, implying at best only a small increase in the $\mathrm{H}$ concentration. ${ }^{3}$ Doping effects are readily apparent at rather low levels of doping, implying that defect compensation plays a minor role. Further measurements of the density of gap states, the electron affinity, and the band structure are necessary to elucidate the doping mechanism.

\section{CONCLUSIONS}

We have demonstrated controlled doping of semiconducting boron carbide thin films grown by PECVD using $\mathrm{Ni}$ as a n-type dopant. The overall trend from $\mathrm{p}$ to $\mathrm{n}$ was investigated as a function of dilution ratio which was controlled by the source molecule's flow rate. Doping does not affect the surface roughness but does alter the crystal structure. Incorporation of $\mathrm{Ni}$ into the $\mathrm{BC}$ film was shown to be relatively inefficient; however, even these small quantities of dopant are shown to notably affect the electronic properties. Over the range of doping investigated, there is a significant change in the position of the Fermi level as measured by the built-in voltage. The controlled doping of semiconducting boron carbide over this large range is extremely promising for future applications in neutron detectors and magnetic tunnel junctions.

\section{ACKNOWLEDGMENTS}

This research at UNL was supported by the NASA under Grant Nos. NNG05GM89G and NSF-0725881, the Defense Threat Reduction Agency (Grant No. HDTRA1-09-1-0060), and also the Nebraska Research Initiative. The operation of CAMD is supported by the State of Louisiana. We would like to acknowledge the staff of CAMD for their support in the XANES studies.

${ }^{1}$ G. Braunstein, A. Muraviev, H. Saxena, N. Dhere, V. Richter, and R. Kalish, Appl. Phys. Lett. 87, 192103 (2005).

${ }^{2}$ D. Byun, B. R. Spady, N. J. Ianno, and P. A. Dowben, Nanostruct. Mater. 5, 465 (1995).

${ }^{3}$ D. N. Mcllroy, S.-D. Hwang, K. Yang, N. Remes, P. A. Dowben, A. A. Ahmad, N. J. Ianno, J. Z. Li, J. Y. Lin, and H. X. Jiang, Appl. Phys. A: Mater. Sci. Process. 67, 335 (1998).

${ }^{4}$ B. W. Robertson, S. Adenwalla, A. Harken, P. Welsch, J. I. Brand, P. A. Dowben, and J. P. Claassen, Appl. Phys. Lett. 80, 3644 (2002).

${ }^{5}$ E. Day, J. Diaz, and S. Adenwalla, J. Phys. D: Appl. Phys. 39, 2920 (2006).

${ }^{6}$ S. Adenwalla, P. Welsch, A. Harken, J. I. Brand, A. Sezer, and B. W. Robertson, Appl. Phys. Lett. 79, 4357 (2001).

${ }^{7}$ D. S. McGregor, S. M. Vernon, H. K. Gresch, S. M. Markham, S. J. Wojtczuk, and D. K. Wehe, IEEE Trans. Nucl. Sci. 47, 1364 (2000).

${ }^{8}$ L. Bernard, A. N. Caruso, B. Xu, B. Doudin, and P. A. Dowben, Thin Solid Films 428, 253 (2003).

${ }^{9}$ S.-D. Hwang, N. B. Remmes, D. N. Mcllroy, and P. A. Dowben, J. Vac. Sci. Technol. B 14, 2957 (1996).

${ }^{10}$ Sigma-Aldrich, http://www.sigmaaldrich.com.

${ }^{11}$ L. A. Torres-Gómez, G. Barreiro-Rodriguez, and F. Mendez-Ruiz, Thermochim. Acta 124, 179 (1988).

${ }^{12}$ H. A. Pathak, P. M. Raole, C. Jariwala, P. Semwal, and Y. C. Saxena, Fusion Engineering 2005, 21st IEEE/NPS Symposium, 2005 (unpublished), pp. 1-4.

${ }^{13}$ M. Lemonnier, O. Collet, C. Depautex, J. M. Esteva, and D. Raoux, Nucl. Instrum. Methods Phys. Res. A 152, 109 (1978).

${ }^{14}$ M. Becerril, O. Zelaya-Angel, R. Ramirez-Bon, F. J. Espinoza-Beltran, and J. Gonzalez-Hernandez, Appl. Phys. Lett. 70, 452 (1997).

${ }^{15}$ K. Ploog and M. Druminski, Krist. Tech. 9, 25 (1974).

${ }^{16} \mathrm{H}$. Werheit, R. Schmechel, V. Kueffel, and T. Lundstrom, J. Alloys Compd. 262-263, 372 (1997).

${ }^{17}$ A. Yu. Ignatov, Ya. B. Losovyj, L. Carlson, D. LaGraffe, J. I. Brand, and P. A. Dowben, J. Appl. Phys. 102, 083520 (2007).

${ }^{18}$ C. D. Wagner, W. M. Rigg, L. E. Davis, J. F. Moulder, and G. E. Mullenberg, Handbook of X-Ray Photoelectron Spectroscopy (Physical Electronics, Eden Prairie, MN, 1979).

${ }^{19}$ P. A. Dowben, O. Kizilkaya, J. Liu, B. Montag, K. Nelson, I. Sabirianov, and J. I. Brand, Mater. Lett. 63, 72 (2009).

${ }^{20}$ I. Jiménez, L. J. Terminello, F. J. Himpsel, M. Grush, and T. A. Callcot, J. Electron Spectrosc. Relat. Phenom. 101-103, 611 (1999). 
${ }^{21}$ I. Jiménez, D. G. J. Sutherland, T. van Buuren, J. A. Carlisle, L. J. Terminello, and F. J. Himpsel, Phys. Rev. B 57, 13167 (1998).

${ }^{22}$ S. Lee, J. Mazurowski, R. Ramseyer, and P. A. Dowben, J. Appl. Phys. 72, 4925 (1992).

${ }^{23}$ C. Wood and D. Emin, Phys. Rev. B 29, 4582 (1984).

${ }^{24}$ W. R. Frensley and H. Kroemer, Phys. Rev. B 16, 2642 (1977).
${ }^{25}$ W. E. Spear, Adv. Phys. 26, 811 (1977).

${ }^{26}$ W. B. Jackson, Phys. Rev. B 41, 12323 (1990).

${ }^{27}$ W. E. Spear, G. Willeke, P. G. LeComber, and A. G. Fitzgerald, J. Phys. (Paris) 42, C4 (1981).

${ }^{28}$ M. Taniguchi, M. Hirose, Y. Osaka, and S. Hasegawa, Jpn. J. Appl. Phys. 19, 665 (1980). 